\title{
PROFESSIONAL APPROACH ON WOMEN WITH BREAST CANCER: A LEARNING PROCESS
}

\author{
Mayara M. P. Carvalho¹, Ana Luiza L. Sousa¹, Márcia F. Veloso', Ruffo Freitas-Junior ${ }^{1}$ \\ ${ }^{1}$ CORA - Centro Avançado de Diagnóstico da Mama, Hospital das Clínicas, Universidade Federal de Goiás - Goiânia (GO), Brazil.
}

Background: The female sexuality is a poor studied subject, even less researched concerning situations in which the woman faces the diagnosis for breast cancer. The disease brings the patient a new perspective of themselves. It is such as making a new identity to awake, somehow due to the finding of the cancer. Psychologically, the woman is not sick by the time she gets to the practitioner; the patient comes down with the process triggered by the diagnosis and clinic picture. Therefore, the family gets involved, specially the partner. Objective: Researching how the breast cancer diagnosis may influence the couple relationship dynamics, as well as the female sexuality itself. Methodology: This study was held in a reference support center for women with breast cancer. Validated instruments were used to evaluate the sexual dysfunction of women and their partners at the moment they received the diagnosis, and in an average time of three months treatment. All parties involved were volunteers and agreed freely to take part in this study. Results: We went through nerve-wracking and stress times when part of the women researched stood against us, heading towards the institution Ombudsman, ignoring the confidentiality in terms of the approach. Complaints about intrusive and embarrassing subjects were made; they claimed the language used in the interviews were inappropriate. The problem was solved by clarifying the misunderstandings and by reinforcing their contribution to the study. On the other hand, there were significant contribution on the part of the ones who identified in the approach the opportunity to express their deepest inner feelings. Conclusion: The human wholeness should not be forgotten in the sickening process, disregarding the person who falls ill, only focusing on the illness. Thereby, capable multidisciplinary teams are required for this kind of holistic approach. 